Artigo de Reflexão/Ensaio

\title{
Vulnerabilidade social e Covid-19: consideraçóes com base na terapia ocupacional social
}

\section{Social vulnerability and Covid-19: considerations based on social occupational therapy}

\author{
Magno Nunes Farias ${ }^{a}$ (D), Jaime Daniel Leite Junior ${ }^{a}$ (D) \\ ${ }^{a}$ Universidade Federal de São Carlos - UFSCar, São Carlos, SP, Brasil.
}

Como citar: Farias, M. N., \& Leite Junior, J. D. (2021). Vulnerabilidade social e Covid-19:

consideraçóes com base na terapia ocupacional social. Cadernos Brasileiros de Terapia Ocupacional, 29, e2099. https://doi.org/10.1590/2526-8910.ctoEN2099

\begin{abstract}
$\underline{\text { Resumo }}$
A terapia ocupacional social se localiza ao longo da história como subárea que se constrói no Brasil, principalmente na emergência de estudar, pesquisar e questionar temas relacionados às contradiçôes e injustiças sociais da sociedade capitalista, propondo ações terapêutico-ocupacionais que buscam o seu enfrentamento. No contexto da pandemia da COVID-19, os abismos postos por essas contradiçóes têm ficado cada vez mais evidentes, nacional e globalmente, tendo em vista a desigualdade estrutural existente. A populaçáo em vulnerabilidade social é a maior impactada pelos seus efeitos, dada a ausência e/ou insuficiência de recursos, estratégias de prevençáo e/ou tratamento da doença em seus cotidianos, associados às dificuldades de realizar o isolamento social, a manutenção do emprego e da renda, bem como o menor acesso à saúde e ao saneamento básico. Frente a isso, compreendese que as questôes macrossociais têm relação direta com o desenvolvimento da doença e a forma como afeta os diferentes grupos populacionais. Desta forma, destaca-se a importância das contribuiçóes da terapia ocupacional social, no âmbito da pesquisa e/ou intervenção, baseadas em um pensar/fazer que acolha os desejos e as necessidades dos indivíduos e grupos, que problematize os impactos das desigualdades estruturais na vida cotidiana, que fortaleça movimentos de afirmaçáo da vida, da autonomia, da cidadania e dos direitos. Por fim, fomentando estratégias de igualdade e reconhecimento, na democratizaçáo das possibilidades de dar continuidade à vida em meio e após a pandemia.
\end{abstract}

Palavras-chave: Terapia Ocupacional/Tendências, Infecçôes por Coronavirus, Pandemias, Vulnerabilidade Social, Terapia Ocupacional Social. 


\section{$\underline{\text { Abstract }}$}

Social occupational therapy has been located throughout history as a subarea that is built in Brazil, mainly on the emergence of studying, researching, and questioning themes related to the social contradictions and injustices of capitalist society, proposing occupational therapy's actions that seek to face them. In the context of the COVID-19 pandemic, the chasms created by these contradictions have become increasingly evident, nationally and globally, given the existing structural inequality. The population in social vulnerability is the most impacted by its effects, given the absence and/or insufficiency of resources, prevention strategies, and/or treatment of the disease in their everyday lives, associated with the difficulties of executing social isolation, maintaining employment, and income, as well as less access to health and basic sanitation. Given this, it is understood that macrosocial issues are directly related to the development of the disease and the way it affects different groups. In this way, it is emphasized the importance of the contributions of occupational social therapy, within the scope of research and/or intervention, based on thinking/doing that embraces the wants and needs of individuals and groups, which problematizes the impacts of structural inequalities in everyday life, what strengthens life-affirming movements, autonomy, citizenship, and rights. Finally, promoting strategies for equality and recognition, in the democratization of the possibilities of continuing life in the pandemic and beyond.

Keywords: Occupational Therapy/Trends, Coronavirus Infections, Pandemics, Social Vulnerability, Social Occupational Therapy.

\section{Introduçáo}

A terapia ocupacional social tem se debruçado sobre as problemáticas que limitam a participação social daqueles sujeitos e coletivos que vivenciam cotidianos marcados pelas vulnerabilidades sociais, econômicas e culturais - em um contexto global de injustiças. Assim, busca contribuir teórica, metodológica e operacionalmente para a transformação dessas questôes, propondo açôes que objetivam o enfrentamento das situaçóes de pobreza e desigualdade, em prol do alargamento das possibilidades de vida e acesso a bens sociais e cidadania (Lopes, 2016; Barros et al., 2007).

Dessa forma, esta subárea de conhecimento e prática se localiza ao longo da história como um referencial teórico-metodológico que se constrói no Brasil, principalmente na emergência de estudar, pesquisar e questionar temas relacionados às contradiçóes e desigualdades da sociedade capitalista, propondo açóes terapêutico-ocupacionais que buscam o enfrentamento destas (Lopes, 2016; Barros et al., 2007). No contexto da pandemia da COVID-19, causada pelo SARS-CoV-2 ${ }^{1}$ (Organização Pan-Americana da Saúde, 2020), os abismos dessas disparidades sociais têm ficado mais evidentes, nacional e globalmente (Lima et al., 2020; Pires, 2020). A população pobre é a mais impactada

\footnotetext{
${ }^{1} \mathrm{O}$ início da disseminação da COVID-19 ocorreu na província de Hubei, na China, e vem se alastrando rapidamente por todos os continentes. A Organização Mundial da Saúde (OMS), em 11 de março de 2020, caracterizou os surtos da doença como uma pandemia. Foram confirmados no mundo 9.473.214 casos e 484.249 mortes até 26 de junho de 2020 (Organização PanAmericana da Saúde, 2020).
} 
pelos seus efeitos, dada a ausência e/ou insuficiência de recursos, estratégias de prevenção e/ou tratamento da doença nos seus cotidianos, "[...] seja pela maior dificuldade de manter o isolamento social, o emprego e a renda, seja pelo menor acesso à saúde e ao saneamento básico [...]" (Pires et al., 2020, p. 1).

Com base nesse panorama, este ensaio busca contribuir para o debate sobre a população em vulnerabilidade social e a pandemia da COVID-19, objetivando realizar uma reflexão crítica sobre as injustiças e desigualdades nessa conjuntura, e também pensar as possibilidades de contribuiçóes da terapia ocupacional social, tanto no âmbito das práticas quanto da produção de conhecimento frente a essas questóes.

\section{Desigualdade Estrutural na Sociedade Capitalista}

Para Castel (2000, p. 238), a questão social é

[...] uma dificuldade central, a partir da qual uma sociedade se interroga sobre sua coesão e tenta conjurar o risco de sua fratura. É, em resumo, um desafio que questiona a capacidade de uma sociedade de existir como um todo, como um conjunto ligado por relaçôes de interdependência.

Desta forma, coloca-se dentro da complexidade da ampla estrutura social, especialmente nas relaçóes de exploração baseadas na dinâmica capital-trabalho, e é uma manifestação inseparável do capitalismo. Sua causalidade se deve a elementos históricos, políticos, culturais etc., baseados na relação antagônica e controvérsia entre a capacidade social de produzir riqueza e um grande contingente de membros sem condiçóes materiais de vida - é fruto então de uma escassez socialmente produzida, erguida sob o comando do capital (Netto, 2006; Castel, 2000).

Esses arranjos desiguais se estruturam com base na "lei geral da acumulação capitalista”, e ocorrem em mediação com elementos culturais, geopolíticos e históricos (associados a aspectos de classe, étnico-racial, de gênero, sexualidade, território, geracional) que são estabelecidos em todo o mundo, mas com a especificidade de cada constituição nacional. As consequências da globalização do capital, do neoliberalismo, da incerteza do mundo do trabalho e do desmantelamento dos sistemas de proteção social caracterizam as novas manifestaçôes da questão social na sociedade moderna (Netto, 2006), que expóe um contingente de sujeitos e coletivos à vulnerabilidade social, compreendida como resultado do trabalho precarizado e da fragilidade da rede de apoio, relacional e institucional (Castel, 2000).

Para Nosella (2008, p. 267), “[...] o principal problema ético da atualidade é decorrente da contradição entre uma superconcentração de riquezas e o aumento desmedido da pobreza. Poucos centros de riquezas, de um lado, e enormes regióes de misérias, de outro". Assim, corroboramos o autor na compreensão de que essas injustiças sociais são uma questão ética na sociedade contemporânea, pois o desejo de resolvê-las é uma opção política, tendo em vista que os recursos são existentes.

Assim, com base em Fraser (2006), entende-se que a questão social produz injustiças nos âmbitos econômico e cultural, marcados pela exploração dos trabalhadores, marginalização da economia e privação do acesso à vida material, bem como pelas lógicas de dominação cultural, desqualificação e desrespeito. Aspectos estes que perpassam a má 
distribuição econômica e o reconhecimento distorcido, que marcam o cotidiano de populaçôes em vulnerabilidade social.

Nas contradiçóes da sociedade capitalista, a construção de cidadania e direitos sociais, em diálogo com os direitos civis e políticos, é configurada como estratégias para reduzir tais injustiças e desigualdades (Lopes, 2016). Estes dependem, em certa medida, do consenso da sociedade e reivindicaçóes coletivas - inclusive da classe trabalhadora - para proporcionar melhores condiçôes para a sobrevivência de grupos socialmente desfavorecidos. Assim, as políticas públicas, sobretudo as sociais, são maneiras que os Estados constroem "[...] para a redistribuição dos benefícios sociais visando a diminuição das desigualdades estruturais produzidas pelo desenvolvimento socioeconômico [...]" (Höfling, 2001, p. 31). No entanto, essa lógica ainda se alicerça sobre a razão capitalista que, via uma estruturação de ordem neoliberal, faz com que se produza essas políticas ainda de forma inadequada e insuficiente, tendo em vista que existe um contingente populacional que sofre diariamente com a falta de serviços de saúde, educaçáo, instalaçóes sanitárias, entre outras coisas, acabando por realizar a manutenção das desigualdades sociais - tendo em vista que a esfera da cidadania ainda é limitada para muitos (Costa \& Costa, 2016; Höfling, 2001).

Os dados do relatório Montando o Quebra-Cabeça da Pobreza demonstram os abismos dessa desigualdade social, indicando que quase metade da população mundial - 3,4 bilhóes de pessoas - ainda vivem em situação de pobreza, lutando cotidianamente para satisfazer necessidades básicas - como acesso a saneamento, água tratada e potável, eletricidade e serviços de educação e saúde (World Bank Group, 2018). O Rastreando a cobertura universal de saúde: Relatório de monitoramento global de 2017 indica que ao menos metade das pessoas no mundo não têm acesso aos serviços essenciais de saúde, e a cada ano um grande número - cerca de 100 milhões - de famílias são levadas à situação de pobreza por terem que pagar por esses serviços, demonstrando o déficit de políticas sociais globais nesse âmbito (World Health Organization, 2017).

No Brasil, esse panorama não é diferente, mantendo-se como um dos países mais desiguais do mundo. Em 2015, identificou-se que a soma entre a populaçáo abaixo da linha da pobreza multidimensional ${ }^{2}$ e a população vulnerável à pobreza representa quase $50 \%$ do país - 100 milhóes de pessoas (Silva et al., 2020). Estas são consequência das barreiras de acesso à educação, saúde, saneamento básico, emprego e renda (Pires et al., 2020; Costa \& Costa, 2016; Pires, 2020).

Assim, as vidas cotidianas ${ }^{3}$ (Galheigo, 2020) das populações vulneráveis envolvem problemáticas sociais, culturais, econômicas, políticas e territoriais, com dificuldades relacionadas à inserção e participação social. Suas experiências são marcadas pelas dificuldades de acesso a bens sociais necessários para a própria manutenção da vida, individual e coletiva, limitando a vivência de atividades significativas para si e para o seu grupo de pertencimento. Estes aspectos ficam ainda mais evidentes em situaçóes limites, como as impostas pelo contexto de pandemia da COVID-19, nas quais vidas precárias,

\footnotetext{
${ }^{2}$ A pobreza multidimensional envolve questôes além da renda, como acesso à água tratada, condiçóes sanitárias, indicador de propriedade, entre outras (Silva et al., 2020).

${ }^{3}$ Refere-se aqui aos processos mais amplos que envolvem os sujeitos para a compreensão de cotidiano. Entende-se que a categoria cotidiano não se apega a modelos objetivos para compreensão da realidade social, buscando entender a vida de todos os dias enquanto lugar de circulação subjetiva, cultural, política, econômica e histórica, dentro das experiências vividas, desejos e sonhos (Galheigo, 2020).
} 
dentro de uma política de desigualdade, ficam ainda mais passíveis à morte, e a opressão em eminência se coloca como necrófila (Freire, 1987), para além do sentido simbólico, enunciando sobre quais vidas são passíveis de morrer.

\section{Impactos da Pandemia para as Populaçóes em Vulnerabilidade Social}

A relação entre epidemia/pandemia e vulnerabilidade social já foi constatada em outros momentos históricos, como nos casos da gripe espanhola, H1N1 (Gripe Suína) e SARS (Síndrome Respiratória Aguda Grave), constatando que as desigualdades sociais "[...] são determinantes para a taxa de transmissão e severidade dessas doenças [...]" (Pires et al., 2020, p. 1). Aqui, busca-se pensar quais os impactos da COVID-19 em populaçóes vulneráveis socialmente, rompendo com a ideia de uma doença democrática (Calmon, 2020). Passa-se pelas problemáticas que envolvem o isolamento social e as demais recomendaçóes de prevenção ${ }^{4}$, mas se mira, principalmente, na compreensão de como as questóes macrossociais têm relaçáo direta com o desenvolvimento da doença e a forma como afeta os diferentes grupos populacionais.

Nesse sentido, os grupos que vivenciam os cotidianos de maior pobreza estão mais expostos à COVID-19. Por exemplo, os dados coletados pelo Departamento de Saúde da cidade de Nova York colocam que os bairros urbanos mais pobres da cidade estáo sendo mais afetados, não necessariamente pelo número de casos, mas por um índice maior de gravidade, dadas outras fragilidades associadas ao acesso de recursos necessários para tratamentos ou outras comorbidades que já atingem essa população (Pires et al., 2020).

Estudos, como o de Pires et al. (2020), vêm apontando como a COVID-19 impacta diferentemente os países e regióes mais pobres do mundo, visto que as populaçóes de baixa renda usam com mais frequência o transporte público, possuem maior número de moradores por domicílio, têm menor acesso ao saneamento básico e saúde, além das dificuldades de manterem o isolamento social devido a suas características de emprego e renda. As autoras ainda analisaram os dados da Pesquisa Nacional de Saúde (PNS), realizada no Brasil em 2013, pelo Instituto Brasileiro de Geografia e Estatística (IBGE), relacionando uma conexão entre idade, escolaridade e doenças crônicas e os casos mais graves de COVID-19 no país.

Se considerarmos como fatores de risco ter acima de 60 anos, ter sido diagnosticado com diabetes, hipertensão arterial, asma, doença pulmonar, doença cardíaca ou insuficiência renal crônica, a PNS sugere que $42 \%$ da população se encontra em algum grupo de risco. No entanto, os fatores de risco tampouco parecem estar distribuídos igualmente na população (Pires et al., 2020, p. 2).

No panorama brasileiro, os menores índices de escolaridade estão diretamente ligados às camadas mais pobres. Com base nisso, a pesquisa das autoras, fundamentada nos dados da PNS de 2013, evidenciaram que a maior proporção de brasileiros com um ou mais fatores de risco (54\%) frequentou até o Ensino Fundamental. Mais que isso, constatou-se que, independentemente da idade, a incidência de comorbidades (doenças

\footnotetext{
${ }^{4}$ As medidas de prevenção da COVID-19 envolvem o isolamento e distanciamento social, lavar as mãos com água e sabão ou com desinfetantes adequados à base de álcool (Organização Pan-Americana da Saúde, 2020).
} 
crônicas associadas aos casos mais graves de COVID-19) também é maior entre as pessoas com menor nível de escolaridade (42\%), elevando consideravelmente o risco deste grupo.

Fazendo um recorte sobre a população negra brasileira, que ainda ocupa os lugares de maior pobreza no país, a Pública - Agência de Jornalismo Investigativo publicou um estudo, com base nos dados do Ministério da Saúde (MS $)^{5}$, que mostra que o número de pessoas negras que morreram por COVID-19 no Brasil, nas semanas de 11 a 26 de abril de 2020, aumentou cinco vezes ${ }^{6}$. Ainda, relatou um aumento de 5,5 vezes de brasileiros negros hospitalizados com SARS, motivada por COVID-19, sendo uma morte a cada 3,1 internaçóes ${ }^{7}$. Essa realidade é diferente quando comparada com a população branca, em que o número de mortes e hospitalização aumentou pouco mais que o triplo, ocorrendo uma morte a cada 4,4 internaçóes (Muniz et al., 2020). Rita Borret, coordenadora do Grupo de Trabalho de Saúde da População Negra da Sociedade Brasileira de Medicina de Familia e Comunidade, aponta que não existe uma questáo biológica para maior incidência nas pessoas negras. A questão central é o racismo e a forma como ele opera, dificultando o acesso desta população aos serviços de saúde (Muniz et al., 2020).

Esta realidade não é apenas nacional; nos Estados Unidos da América, a COVID-19 também tem sido mais letal na população negra e pobre. O país ofereceu pouca transparência das informaçóes raciais da pandemia, o que foi mudando, posteriormente, devido ao mapa produzido pela John Hopkins University (Johns Hopkins Coronavirus Resource Center, 2020), identificando os estados estadunidenses que estavam produzindo recortes raciais. Os dados posteriores foram trazendo um panorama concreto, atestando o maior impacto na população negra (Muniz et al., 2020). Assim, ao se analisar a relação do vírus com a questão étnico-racial, não se pode perder de vista a compreensão do racismo estrutural (Almeida, 2018), que integra a organização social, política, econômica e cultural da sociedade e é responsável por dar sentido, lógica e tecnologia para os processos de desigualdade e violência. Isto se desdobra numa realidade em que a população negra é a mais pobre, em decorrência da histórica exploração deste grupo na divisão social do trabalho.

Portanto, ao relacionar a dimensão do racismo e classe social com o cenário atual, fica posta a necessidade de que, ao mesmo tempo em que o enfrentamento à pandemia deve ocorrer de maneira geral, as ações só se mostrarão, de fato, efetivas se houver estratégias que considerem que a organização social é pautada na desigualdade social. Com isso, urge a emergência de construir e fortalecer políticas que abarquem as especificidades dos diferentes grupos sociais que se encontram nesta situação.

Compreender as especificidades destes grupos em vulnerabilidade social é, por exemplo, reconhecer que a possibilidade de lavar a mão com frequência, o uso de álcool, entre outras recomendaçôes de higiene e segurança são medidas extremamente

\footnotetext{
${ }^{5}$ Conforme relatado pela Agência Pública, o MS não incluiu as fichas de notificação com as informaçóes de raça/cor ignoradas. As informações específicas sobre a população negra começaram a ser divulgadas apenas em 11 de abril de 2020, dada a solicitação do Grupo de Trabalho de Saúde da População Negra da Sociedade Brasileira de Medicina de Família e Comunidade.

${ }^{6}$ De acordo com a Agência Pública, o número passou de pouco mais de 180 para mais de 930.

${ }^{7}$ No estado do Amazonas, a maioria absoluta de mortes são de pessoas negras. Mais de 13 pessoas negras morreram para cada falecimento de pessoa branca. Foram registrados, pela Secretaria de Saúde, cerca de 850 pessoas negras doentes em situação grave e mais de 340 mortes. Com relação à população branca, houveram 81 casos graves e 25 mortes, conforme dados de atualizados em 29 de abril de 2020 (Muniz et al., 2020).
} 
complexas de serem adotadas, principalmente em países onde há déficit na cobertura de saneamento básico. No Brasil, de acordo com os dados de 2018 do Sistema Nacional de Informaçôes sobre Saneamento (SNIS), chega quase a 35 milhóes o número de pessoas que não têm acesso a água tratada e 100 milhóes não possuem esgoto. Logo, fica exposto como "[...] as condiçôes de prevenção e cuidado se impóem de formas diferentes a segmentos sociais distintos, assim como o potencial de letalidade do vírus [...]" (Calmon, 2020, p. 131).

A pobreza extrema é uma ferida exposta. Existem milhares de pessoas vivendo em condições precárias, subempregadas, que dependem do movimento, da circulação, para conseguir alguma renda, algo que garanta a sobrevivência (Calmon, 2020; Muniz et al., 2020). Grande parte desses sujeitos são pessoas subalternizadas (negras, mulheres, dissidentes de gêneros e sexualidades, pessoas com deficiência, entre outros), historicamente em desvantagem na disputa no mercado de trabalho. Nas periferias, favelas e outros espaços de vida destes sujeitos, está um grande aglomerado de trabalhadores e trabalhadoras que compóem os ditos serviços prioritários durante a pandemia. Diferente dos profissionais de saúde, esses serviços não recebem prestígio ou reconhecimento social, a saber: faxineiras, garis, entregadores, empregadas domésticas, motoristas, trabalhadores de supermercados, frentistas de postos de gasolina, entre outros. No geral, estas pessoas dependem das políticas sociais de redistribuição de renda e/ou que vivem em situaçóes empregatícias táo frágeis que a negociação com os patróes não é uma possibilidade.

O processo de expansão da uberização é diretamente ligado a isso. Franco \& Ferraz (2019) explicam que o conceito foi cunhado para dizer da fragilização das relaçóes de trabalho. Pessoas socialmente instáveis que estão sob este regime, em momentos como o atual, ficam ainda mais vulneráveis, visto que não possuem nenhum vínculo empregatício e estão apartadas de usufruir dos direitos destinados a trabalhadores formais. Como trabalhadoras autônomas, assumem variados riscos para que possam prestar o serviço, além de terem que deter - e se responsabilizar - por quase todas as ferramentas necessárias para a execução da tarefa.

Outras populaçóes também carregam marcadores que aumentam seu risco dentro dessa estrutura desigual. A população em situação de rua, em períodos comuns, já enfrenta diversos desafios na busca de cidadania e garantia dos seus direitos (Brasil, 2011). Especialmente agora, é atravessada pela negação do Estado na proposição de estratégias efetivas e direcionadas que favoreçam aos cuidados necessários para prevenir a contaminação e disseminação da doença, inclusive entre os pares.

Os povos indígenas também são diretamente atravessados. Oliveira et al. (2020) apontam o possível cenário devastador que pode ocorrer com a entrada da COVID-19 nos territórios indígenas, dada a alta transmissibilidade da doença, a vulnerabilidade social que as populaçôes isoladas se encontram e a escassez de assistência médica e logística de transporte dos doentes. Os achados da pesquisa apontam a subnotificaçáo nesses lugares como um fator complicador para o controle da transmissão (Oliveira et al., 2020).

A violência doméstica também se coloca como ponto de atenção durante a pandemia, visto que mulheres, pessoas dissidentes de gêneros e sexualidades, crianças, idosos, pessoas com deficiência, entre outros grupos, têm maior potencial de exposição. Os indicadores de países como Brasil, China e Espanha mostram um agravamento dos casos 
já existentes, além de novos casos. Campbell (2020) coloca que é estimado que, no Brasil, as denúncias de violência doméstica tenham aumentado entre 40 e 50\%, e na França o índice está em 30\%. Os números de casos na China estáo três vezes maiores, e na Itália, entre outros países, também estão em ascensão os números de denúncias.

Assim, é fato que a pandemia tem causado severas mudanças na vida cotidiana da população, independente da faixa etária, sendo necessário acionar estratégias, serviços e recursos disponíveis na prevenção e resolução dos problemas colocados, bem como requerendo dos profissionais e pesquisadores fomentar estratégias. Dentre estes, a terapia ocupacional social se coloca como subárea de conhecimento e prática importante nesta luta, podendo oferecer suporte aos grupos em vulnerabilidade social que sáo diferentemente atravessados pelos impactos sociais da doença.

\section{Terapia Ocupacional Social: Articulando pela Justiça Social}

A Federação Mundial de Terapeutas Ocupacionais (WFOT) publicou uma declaração intitulada Resposta de terapeutas ocupacionais à pandemia de COVID-19, reconhecendo os impactos desse fenômeno na realização das atividades cotidianas das pessoas, no âmbito do acesso a recursos, comunicação, mobilidade, saúde mental e bem-estar. Ainda, afirmou o compromisso profissional, junto ao desenvolvimento de estratégias teórico-metodológicas, que contribuam na diminuição dos impactos da doença e possibilitem acesso às atividades necessárias e significativas dos sujeitos e grupos (World Federation of Occupational Therapists, 2020). A Associação Brasileira de Terapeutas Ocupacionais (ABRATO) reiterou esse posicionamento, manifestando em nota o dever ético da profissão em contribuir nesse momento de emergência sanitária (Associação Brasileira dos Terapeutas Ocupacionais, 2020).

Desse modo, explicita-se que as ações terapêutico-ocupacional são importantes na conjuntura, sobretudo para minimizar os impactos na vida daqueles mais vulneráveis, reafirmando que "[...] o trabalho em terapia ocupacional, nos cotidianos dos sujeitos, só se concretiza na luta pela vida possível para todos, em todas as potências e diferenças que lhes dão significado e fazem diminuir as desigualdades" (Malfitano et al., 2020, p. 4). Dado o contexto que aprofunda a questão social e afunila as chances de vida daqueles historicamente marcados pelas desigualdades e injustiças, a terapia ocupacional social tem um repertório importante para auxiliar e contribuir com a busca da justiça social. Compreendemos justiça social com base na paridade de participação social e cotidiana dos sujeitos, pautada no reconhecimento e respeito às diferenças, no acesso a bens sociais e ao trabalho digno, a partir de um compromisso ético, coletivo e político voltado para a oferta dos recursos necessários para a garantia da inserção social (Freire, 1987; Fraser, 2006; Nosella, 2008).

As ações da terapia ocupacional social acontecem dentro do campo social, com base em uma leitura socio-histórica macro e microssocial, apreendendo as questóes estruturais e dos cotidianos de vida, de forma individual e coletiva (Malfitano, 2016). Para tanto, estes profissionais buscam realizar intervençóes "[...] articulando, técnica e politicamente, cidadania, universalização de direitos, políticas sociais, radicalização da democracia [...]" (Lopes, 2016, p. 46), em prol do alargamento do acesso aos direitos e bens sociais que alcancem e tornem possível a vida digna da população (Malfitano et al., 2020). 
Por isso, tem-se como parâmetro central abordar a vida cotidiana na perspectiva dos direitos aos bens sociais básicos aos cidadãos, aqueles que se afirmam no Brasil, a exemplo, pelo sistema de Seguridade Social, firmados na Constituição Brasileira de 1988 (Brasil, 1988), que enunciam o conjunto de açóes que devem assegurar a todos os sujeitos direito à saúde, à previdência e à assistência social, com base em políticas sociais que alcancem e tornem possível a vida digna da populaçáo (Malfitano et al., 2020). Dessa forma, assegurar, fortalecer e articular esse sistema de seguridade e a manutenção e formulação de políticas sociais, em todos os tempos, mas especialmente em tempos que explicitam as disparidades, são aspectos balizadores para a tomada de ação da terapia ocupacional social.

Tendo estas questôes como eixo, na pandemia é possível atuar para constituir, mapear, demarcar e pensar, juntamente aos grupos fragilizados, repertórios de possibilidades cotidianas para a superação de barreiras que impedem a participação social e o acesso aos cuidados necessários para a manutenção da vida humana. Também, na prevenção e tratamento da doença, nas formas de articular mecanismos políticos, sociais, relacionais, instrumentais e financeiros para aqueles que ficam sujeitos a maiores vulnerabilidades, como os que perderam suas fontes de trabalho e renda e/ou estão submetidos à precarização e à violência de forma intensa.

Portanto, são necessárias contribuiçóes no domínio da pesquisa em terapia ocupacional social sobre a pandemia, produzindo e divulgando conhecimentos e práticas com base nas demandas que se impóem nas realidades concretas e emergentes, denunciando as injustiças e propondo formas de cuidado, por exemplo: os impactos sociais da pandemia no cotidiano das populaçóes, uso de tecnologias virtuais para a assistência dos sujeitos, a centralidade das políticas públicas para a ação profissional, construção de ferramentas e políticas para atuação em situações limites, entre outros.

$\mathrm{Na}$ intervenção nos diferentes equipamentos sociais, pode-se agir utilizando das metodologias da subárea, denominadas tecnologias sociais (Lopes et al., 2014). Ainda que não construídas para períodos de pandemia, apostamos que estas podem favorecer o suporte aos grupos em vulnerabilidade nestes momentos. Isto pode se dar atuando com: Oficinas de Atividades, Dinâmicas e Projetos, no âmbito do trabalho junto a sujeitos e coletivos nos diferente serviços para pensar os impactos da pandemia e as estratégias de prevenção e conscientização; Acompanhamentos Singulares e Territoriais, junto àqueles que necessitam de maiores cuidados em seus territórios, dadas as dificuldades individuais de mobilidade, circulação, relacionais, familiares e de acesso; Articulação de Recursos no Campo Social, provendo esforços na busca de recursos suficientes para os cuidados sejam advindos dos órgãos públicos, movimentos sociais e comunidade - para aqueles que perderam suas redes de suporte pelas novas dinâmicas sociais, no campo das relaçôes e trabalho. Exemplo disso é divulgar e garantir o acesso às políticas públicas emergenciais de transferência de renda ${ }^{8}$; e, por fim, Dinamização da Rede de Atenção, realizando orientaçóes juntos às suas equipes, fortalecendo o debate sobre políticas públicas e as especificidades necessárias para a conjuntura atual, bem como estimulando que as notificaçôes de COVID-19 sejam realizadas de maneira completa, com dados sobre o

${ }^{8}$ O Auxílio Emergencial, instituído pela Lei no 13.982 de 02 de abril de 2020, é um benefício financeiro voltado aos trabalhadores informais, microempreendedores individuais (MEI), autônomos e desempregados, com o objetivo de fornecer proteção emergencial no período de enfrentamento à crise causada pela pandemia da COVID-19 (Brasil, 2020). 
território, raça, gênero, entre outros, possibilitando mapear quem são os sujeitos mais acometidos e quais as necessidade políticas frente a isso. Contudo, também se faz necessário pensar a construção e aprimoramento das ferramentas para que sejam utilizadas remotamente, tendo em vista os desafios que dizem respeito ao domínio dos dispositivos tecnológicos (smartphones, computadores, acesso à internet) pelos profissionais e sujeitos de intervenção, mas, sobretudo, levando em consideração a desigualdade de acesso a estes bens pela população alvo da terapia ocupacional social.

Cabe destacar ainda os desafios de agir em um contexto global de crise social, econômica e da própria democracia, e que atinge especialmente o Brasil. Vivemos uma política de desmonte dos direitos sociais. Em 15 de dezembro de 2016, foi aprovada a Emenda Constitucional 95 (EC 95), com novo regime fiscal para os próximos 20 anos, colocando um limite para os gastos do governo federal, levando ao sucateamento das políticas sociais. Atualmente, o governo federal - representado por Jair Messias Bolsonaro - tem fortalecido este desmonte, beneficiando os interesses das elites dominantes em detrimento das condiçóes de vida digna para a população. Em meio à pandemia, essa postura não é diferente. Os discursos do presidente priorizam a questáo econômica, e não as vidas humanas, advogando pelo fim do isolamento social, legitimando o "sacrifício" de milhares de trabalhadores e trabalhadoras em prol da estabilidade do mercado financeiro (Lima et al., 2020). É necessário que a terapia ocupacional se posicione no combate dessas narrativas, radicalizando um pensar/fazer que privilegie as vidas humanas - e resista à retórica neoliberal, conservadora e necrófila.

Nesse ponto de vista, com base na perspectiva social, a “[...] terapia ocupacional deve contribuir para o equacionamento de questóes impostas pelas contradiçóes sociais e culturais [...]" (Barros et al., 2007, p. 351), lançando mão de suas habilidades em trabalhar problemáticas desenvolvidas com base em conflitos sociais, aprofundadas no contexto da COVID-19. Novamente, é importante realizar uma ação + reflexâo que acolha os desejos e necessidades dos sujeitos e coletivos, que problematize os impactos das desigualdades estruturais na vida cotidiana, a favor de movimentos de resistência, afirmação da vida, autonomia, cidadania e direitos dos sujeitos em situaçáo de vulnerabilidade social, bem como na construção e fortalecimento de políticas sociais.

Ademais, as estratégias não se findam com o passar da pandemia. Deve-se pensar uma agenda da terapia ocupacional social para o período posterior. Algumas projeçóes demonstram que o número da população em vulnerabilidade social deve aumentar em todo o mundo (Comissáo Econômica para a América Latina e o Caribe, 2020), inclusive no Brasil (Pires, 2020). Ocorrerá um aumento de desempregos, subempregos e empregos informais, levando várias famílias à pobreza e à dificuldade de acesso a serviços e bens de consumo. De acordo com a Comissáo Econômica para a América Latina e o Caribe (CEPAL), “[...] a crise terá maiores impactos sobre os mais vulneráveis: pessoas com problemas de saúde subjacentes, idosos, jovens desempregados, subempregados, mulheres, trabalhadores desprotegidos e migrantes, com o consequente aumento da desigualdade [...]" (Comissão Econômica para a América Latina e o Caribe, 2020, p. 5, tradução nossa). Assim, é urgente a necessidade de se reinventar, lançando mão do largo arcabouço teórico-prático construído, mas reconhecendo a necessidade de pensar novas formas de fazer. Com isso, buscar-se-á antever e construir proposiçóes frente a esse cenário que está por vir, no escopo de tecnologias sociais de cuidado - na esfera das intervençóes terapêuticos-ocupacionais, na formulação e articulação de novas políticas e 
programas sociais para estabilização socioeconômica e no debate sobre o papel do Estado na proteção social das populaçóes, que no nosso entendimento também se coloca como a luta pela garantia da seguridade social, por meio do alargamento do acesso ao fundo público pelo povo, o que se daria, por exemplo, com a revogação da EC 95.

Por fim, intenciona-se com este texto um pensar/fazer da terapia ocupacional social pautado na justiça social e na emancipação dos sujeitos, para se ir além dos condicionamentos impostos pela dominação hierárquica que engendra e arraiga múltiplas opressōes (Galheigo, 2016; Fraser, 2006; Nosella, 2008; Freire, 1987). Fomentando estratégias de igualdade e reconhecimento, na democratização das possibilidades de dar continuidade à vida, de forma autônoma e cidadá, em meio à pandemia e após - vislumbrando uma realidade que seja cada vez menos desigual e acreditando, como coloca Freire (2000, p. 20), que "[...] mudar o mundo é táo difícil quanto possível [...]".

\section{Referências}

Almeida, S. L. (2018). O que é racismo estrutural? Belo Horizonte: Letramento; Justificando.

Associação Brasileira dos Terapeutas Ocupacionais - ABRATO. (2020). Nota da ABRATO sobre a Portaria do Ministério da Saúde $n^{\circ}$ 639, de 02 de abril de 2020. Recuperado em 1 de maio de 2020, de https://www.facebook.com/abratonacional/

Barros, D. D., Lopes, R. E., \& Galheigo, S. M. (2007). Terapia ocupacional social: concepçóes e perspectivas. In A. Cavalcanti \& C. R. C. Galvão (Eds.), Terapia ocupacional: fundamentação \& prática (pp. 347-353). Rio de Janeiro: Guanabara Koogan.

Brasil. (1988). Constituição da República Federativa do Brasil. Recuperado em 1 de maio de 2020, de http://www.planalto.gov.br/ccivil_03/constituicao/constituicao.htm

Brasil. (2011). Orientaçôes técnicas Centro de Referência Especializado para população em situação de rua Centro POP: SUAS e população em situação de rua. Brasília: Gráfica e Editora Brasil.

Brasil. (2020). Lei no 13.982 de 02 de abril de 2020. Altera a Lei n. 8.742, de 7 de dezembro de 1993, para dispor sobre parâmetros adicionais de caracterização da situação de vulnerabilidade social para fins de elegibilidade ao benefício de prestaçáo continuada (BPC), e estabelece medidas excepcionais de proteçáo social a serem adotadas durante o período de enfrentamento da emergência de saúde pública de importância internacional decorrente do coronavírus (Covid-19) responsável pelo surto de 2019, a que se refere a Lei n ${ }^{\circ} 13.979$, de 6 de fevereiro de 2020. Diário Oficial [da] República Federativa do Brasil, Brasília, seção 1. Recuperado em 1 de maio de 2020, de http://www.planalto.gov.br/ccivil_03/_ato2019-2022/2020/lei/L13982.htm

Calmon, T. V. L. (2020). As condiçôes objetivas para o enfrentamento ao COVID-19: abismo social brasileiro, o racismo, e as perspectivas de desenvolvimento social como determinantes. NAU Social, 11(20), 131-136.

Campbell, A. M. (2020). An increasing risk of family violence during the COVID-19 pandemic: strengthening community collaborations to save lives. Forensic Science International Reports, 2, 1-3. http://dx.doi.org/10.1016/j.fsir.2020.100089.

Castel, R. (2000). As transformaçôes da questão social. In M. Belfiore-Wanderley, L. Bógus \& M. C. Yazbek (Eds.), Desigualdade e a questão social (pp. 235-272). São Paulo: EDUC.

Comissão Econômica para a América Latina e o Caribe - CEPAL. (2020). América Latina y el Caribe ante la pandemia del COVID-19: efectos económicos y sociales. Informe especial COVID-19. Recuperado em 1 de maio de 2020, de https://repositorio.cepal.org/bitstream/handle/11362/45337/6/S2000264_es.pdf

Costa, R. F. R., \& Costa, G. C. (2016). Pobres no campo, ricos na cidade? uma análise multidimensional da pobreza. Revista de Economia e Sociologia Rural, 54(3), 537-560. 
Franco, D. S., \& Ferraz, D. L. S. (2019). Uberização do trabalho e acumulação capitalista. Cadernos EBAPE.BR, 17(spe), 844-856. https://doi.org/10.1590/1679-395176936.

Fraser, N. (2006). Da redistribuição ao reconhecimento? Dilemas da justiça numa era "pós-socialista". Cadernos de Campo, 15(14-15), 231-239. http://dx.doi.org/10.11606/issn.2316-9133.v15i1415p231-239.

Freire, P. (1987). Pedagogia do oprimido. Rio de Janeiro: Paz e Terra.

Freire, P. (2000). Pedagogia da indignação: cartas pedagógicas e outros escritos. São Paulo: Editora UNESP.

Galheigo, S. M. (2016). Terapia ocupacional social: uma síntese histórica acerca da constituição de um campo de saber e prática. In R. E. Lopes \& A. P. S. Malfitano (Eds.), Terapia ocupacional social: desenhos teóricos e contornos práticos (pp. 49-68). São Carlos: EdUFSCar.

Galheigo, S. M. (2020). Terapia ocupacional, cotidiano e a tessitura da vida: aportes teórico-conceituais para a construção de perspectivas críticas e emancipatórias. Cadernos Brasileiros de Terapia Ocupacional, 28(1), 5-25. http://dx.doi.org/10.4322/2526-8910.ctoAO2590.

Höfling, E. M. (2001). Estado e políticas (públicas) sociais. Cadernos CEDES, 21(55), 30-41.

Johns Hopkins Coronavirus Resource Center - CRC. (2020). Racial data transparency. Which states have released breakdowns of COVID-19 data by race? Recuperado em 1 de maio de 2020, de https://coronavirus.jhu.edu/data/racial-data-transparency

Lima, J. C., Rangel, F., \& Pires, A. S. (2020). Combate à COVID-19 e a falácia da política economicista. Boletim Coletividade - Sociologia na Pandemia - PPGS/UFSCar. Recuperado em 1 de maio de 2020, de http://www.ppgs.ufscar.br/sociologia-na-pandemia-1

Lopes, R. E. (2016). Cidadania, direitos e Terapia Ocupacional. In R. E. Lopes \& A. P. S. Malfitano (Eds.), Terapia ocupacional social: desenhos teóricos e contornos práticos (pp. 29-48). São Carlos: EdUFSCar.

Lopes, R. E., Malfitano, A. S., Silva, C. R., \& Borba, P. L. O. (2014). Recursos e tecnologias em terapia ocupacional social: açóes com jovens pobres na cidade. Cadernos de Terapia Ocupacional da UFSCar, 22(3), 591-602.

Malfitano, A. P. S. (2016). Contexto social e atuação social: generalizações e especialidades na terapia ocupacional. In R. E. Lopes \& A. P. S. Malfitano (Eds.), Terapia ocupacional social: desenhos teóricos e contornos práticos (pp. 117-133). São Carlos: EdUFSCar.

Malfitano, A. P. S., Cruz, D. M. C., \& Lopes, R. E. (2020). Terapia ocupacional em tempos de pandemia: seguridade social e garantias de um cotidiano possível para todos. Cadernos Brasileiros de Terapia Ocupacional, 28(2), 401-404. https://doi.org/10.4322/2526-8910.ctoed22802.

Muniz, B., Fonseca, B., \& Pina, R. (2020). Em duas semanas, número de negros mortos por coronavírus é cinco vezes maior no Brasil. Pública - Agência de Jornalismo Investigativo. Recuperado em 1 de maio de 2020, de https://apublica.org/2020/05/em-duas-semanas-numero-de-negros-mortos-porcoronavirus-e-cinco-vezes-maior-no-brasil

Netto, J. P. (2006). Capitalismo monopolista e serviço social. São Paulo: Cortez.

Nosella, P. (2008). Ética e pesquisa. Educação \& Sociedade, 29(102), 255-273.

Oliveira, U., Soares Filho, B. S., Oviedo, A., Moreira, T., Carlos, S., Ricardo, J., \& Piaz, A. (2020). Modelagem da vulnerabilidade dos povos indigenas no Brasil ao COVID-19. Instituto Socioambiental (ISA). Recuperado em 1 de maio de 2020, de https://www.socioambiental.org/sites/blog.socioambiental.org/files/nsa/arquivos/nota_tecnica_model o_COVID19.pdf\#overlay-context=pt-br/noticias-socioambientais/vulnerabilidade-social-e-motorda-pandemia-de-COVID-19-em-terras-indigenas-mostra-estudo

Organização Pan-Americana da Saúde - OPAS. (2020). Folha informativa - COVID-19 (doença causada pelo novo coronavirus). Recuperado em 1 de maio de 2020, de https://www.paho.org/bra/index.php?option=com_content \&view=article\&id=6101:COVID19\&Ite $\operatorname{mid}=875$ 
Pires, L. L., Carvalho, L., \& Xavier, L. L. (2020). COVID-19 e desigualdade no Brasil. Recuperado em 1 de maio de 2020, de https://www.researchgate.net/publication/340452851_COVID-

19_e_Desigualdade_no_Brasil

Pires, R. R. C. (2020). Os efeitos sobre grupos sociais e territórios vulnerabilizados das medidas de enfrentamento à crise sanitária da COVID-19: propostas para o aperfeiçoamento da ação pública. Instituto de Pesquisa Econômica Aplicada - IPEA. Recuperado em 1 de maio de 2020, de http://www.ipea.gov.br/portal/publicacoes.

Silva, J. J., Bruno, M. A. P., \& Silva, D. B. N. (2020). Pobreza multidimensional no Brasil: uma análise do período 2004-2015. Brazilian Journal of Political Economy, 40(1), 138-160. http://dx.doi.org/10.1590/0101-31572020-2924.

World Bank Group - WBG. (2018). Poverty and shared prosperity - piecing together the poverty Puzzle. Recuperado em 1 de maio de 2020, de https://openknowledge.worldbank.org/bitstream/handle/10986/30418/9781464813306.pdf

World Federation of Occupational Therapists - WFOT. (2020). Public statement - occupational therapy response to the COVID-19 Pandemic. Recuperado em 1 de maio de 2020, de https://www.wfot.org/about/public-statement-occupational-therapy-response-to-the-COVID-19pandemic\#entry:22326.

World Health Organization, \& World Bank Group. (2017). Tracking universal health coverage: 2017 global monitoring report. Recuperado em 1 de maio de 2020, de http://documents.worldbank.org/curated/en/640121513095868125/pdf/122029-WP-REVISEDPUBLIC.pdf

\section{Contribuiçáo dos Autores}

Ambos os autores fizeram parte da concepção,

formulação, escrita e revisão do texto e aprovaram a sua versão final.

\section{Fonte de Financiamento}

Coordenação de Aperfeiçoamento de Pessoal de Nível Superior - Brasil (CAPES) - Código de

Financiamento 001; Fundação de Amparo à Pesquisa do Estado de São Paulo (FAPESP).

\section{Autor para correspondência}

Magno Nunes Farias

e-mail: magnonfarias@hotmail.com

\section{Editora de seçáo}

Ana Paula Serrata Malfitano 